\title{
Primary healthcare professionals’ knowledge, attitude and behavior regarding influenza immunization; 2006-2007 season adverse effect profile
}

\author{
Mistik S, Balci E, Elmali F \\ Erciyes University Medical Faculty, Kayseri, Turkey. smistik@erciyes.edu.tr
}

\begin{abstract}
Objective: The objective of this study was to assess primary healthcare professionals' knowledge, attitude and behavior regarding immunization, as well as to evaluate the adverse effect profile for the 2006-2007 influenza vaccines.

Background: Influenza vaccination has been proven to have clinical and epidemiological benefits. However, its uptake in the general population and among healthcare workers has generally been suboptimal.

Methods: Primary healthcare professionals of Kayseri were enrolled in the study. Of the 672 primary healthcare professionals in Kayseri, $552(82 \%)$ completed a questionnaire comprised of 19 questions. The study was performed in March 2007 following a campaign of the Ministry of Health of Turkey for influenza vaccination of primary healthcare workers.

Results: Of the health professionals, $67 \%$ (370) were women and $33 \%(182)$ were men. Overall, 420 (76.1\%; $95 \%$ confidence interval: $\mathrm{Cl}=72.3-79.5)$ health professionals reported that they had received influenza vaccine during the 2006-2007 influenza season. Adverse effects were reported by 157 (28.4\%) health professionals. The adverse effects reported were fever $(n=57 ; 13.5 \%)$, muscle pain $(n=60 ; 14.2 \%)$, joint pain $(n=40 ; 9.5 \%)$, loss of appetite $(n=16 ; 3.8 \%)$, headache $(n=41 ; 9.7 \%)$, cough $(n=29 ; 6.9 \%)$, malaise $(n=76 ; 18.0 \%)$, tiredness ( $n=41 ; 9.7 \%)$, stuffiness $(n=49 ; 11.6 \%)$, sneezing $(n=54 ; 12.8 \%)$, sore throat $(n=33 ; 7.8 \%)$ and others, namely erythema, edema and abscess at the vaccination site, and lymphadenopathy $(n=14 ; 3.3 \%)$.

Conclusion: Our study demonstrated that primary health care professionals in our study group have been vaccinated with influenza vaccine in a reasonable percentage. There were no severe or serious adverse effects of the vaccine, the fact of which may be used to encourage both health professionals and patients of primary care (Tab. 3, Ref. 13). Full Text in PDF www.elis.sk.

Key words: influenza vaccination, primary care, health professionals, adverse effects.
\end{abstract}

Influenza is a febrile disease seen almost every winter and caused by influenza A and B viruses. Every year 5-20\% of the population of the United States of America is having influenza. Two hundred thousand patients are being hospitalized due to the complications of it, and 36,000 deaths occur due to influenza. In Germany, 600 patients die because of AIDS, 8,000 due to traffic accidents, whereas 16,000 deaths due to influenza have been reported (1-3).

Vaccination is necessary for primary protection from influenza $(4,5)$. Health professionals are the target group for influenza vaccination because of their increased risk. Vaccination of health care workers has been shown to be associated with a significant decrease in patient mortality (6).

Erciyes University Medical Faculty, Kayseri, Turkey

Address for correspondence: S. Mistik, MD, Erciyes University Medical Faculty, Department of Family Medicine, TR-38039, Kayseri, Turkey. Phone: +90.352.4374937/23851, Fax: +90.352.4375285

Acknowledgement: Authors have no financial or proprietary interest in any instrument or products used in this study. This study has been presented as a poster at the EGPRN Meeting in Vilnius, Lithuania, 27-30 September 2007.
The most common adverse events associated with inactivated influenza vaccines are reported to include local inflammatory reactions such as pain, erythema, and induration. These occur in up to $65 \%$ of recipients. Systemic reactions including fever, myalgia, arthralgia, and headache may appear after vaccination. They occur at a frequency of $1 \%$ to $5 \%$ (7).

\section{Objective}

The aim of this study was to evaluate the knowledge, attitude and behavior of health professionals who are the target group for influenza vaccination. In addition, it was also planned to evaluate the adverse effects of the vaccine for the 2006-2007 season.

\section{Methods}

Subjects

Primary healthcare professionals of Kayseri were included in the study. Of the 672 primary healthcare professionals in Kayseri, 552 (82 \%) have completed a questionnaire. The study was performed in March 2007 following a campaign conducted by the 
Ministry of Health of Turkey for influenza vaccination of primary healthcare workers.

The primary healthcare professionals consist of doctors, nurses, midwives, health clerks, laboratory technicians, x-ray technicians and other clerks (secretaries and drivers).

Erciyes University Medical Faculty Ethical Committee has approved this study.

Questionnaire

A questionnaire comprising 19 questions has been administered to primary healthcare professionals.

A comprehensive standardized questionnaire designed to evaluate the vaccination status of diabetes mellitus patients by Wahid et al. was used (8). Our data collected by direct questioning included age, gender, marital status, occupation, level of education, family's monthly income and presence of chronic diseases.

The questionnaire was validated for Turkey. A pilot study was performed before commencing the study.
Tab. 1. Adverse effects profile.

\begin{tabular}{lcc}
\hline Adverse effect & $\mathrm{n}$ & $\%$ \\
\hline Malaise & 76 & 18.0 \\
Muscle pain & 60 & 14.2 \\
Fever & 57 & 13.5 \\
Sneezing & 54 & 12.8 \\
Stuffiness & 49 & 11.6 \\
Headache & 41 & 9.7 \\
Tiredness & 41 & 9.7 \\
Joint pain & 40 & 9.5 \\
Sore throat & 33 & 7.8 \\
Cough & 29 & 6.9 \\
Loss of appetite & 16 & 3.8 \\
Others* & 14 & 3.3 \\
\hline
\end{tabular}

*Erythema, edema, and one case of abscess at the vaccination site and lymphadenopathy

Tab. 2. Vaccination status and statistical significances according to demographic properties.

\begin{tabular}{|c|c|c|c|}
\hline & $\begin{array}{c}\text { Non-vaccinees } \\
\text { Prevalence n (\%) }\end{array}$ & OR 95\% CI & $\begin{array}{c}\text { Statistical Significance } \\
\text { P value } \\
\end{array}$ \\
\hline \multicolumn{4}{|l|}{ Age (years) } \\
\hline $20-29(n=118)$ & 31 ( 26.3) & 1 & \\
\hline $30-39(n=361)$ & $83(23.0)$ & $0.838(0.520-1.351)$ & \\
\hline$\underline{40+\quad(n=73)}$ & $18(24.7)$ & $0.918(0.469-1.798)$ & 0.776 \\
\hline \multicolumn{4}{|l|}{ Sex } \\
\hline Male (n=182) & 37 (20.3) & 1 & \\
\hline Female $(n=370)$ & $95(25.7)$ & $1.354(0.881-2.081)$ & 0.166 \\
\hline \multicolumn{4}{|l|}{ Marital status } \\
\hline Married (n=492) & 117 (23.8) & 1 & \\
\hline Single $(n=60)$ & $15(25.0)$ & $1.068(0.575-1.986)$ & 0.834 \\
\hline \multicolumn{4}{|l|}{ Education } \\
\hline Illiterate-Elementary school (n=8) & $2(25.0)$ & 1 & \\
\hline High school $(n=202)$ & 48 (23.8) & $0.935(0.183-4.786)$ & \\
\hline University graduate $(n=342)$ & $82(24.0)$ & $0.946(0.187-4.778)$ & 0.996 \\
\hline \multicolumn{4}{|l|}{ Income level } \\
\hline 222 Euros or less (n=3) & $1(33.3)$ & 1 & \\
\hline 222-388 Euros (n=32) & $5(15.6)$ & $0.370(0.028-4.903)$ & \\
\hline 389-833 Euros (n=251) & 56 (22.3) & $0.574(0.051-6.451)$ & \\
\hline 834 and more Euros $(n=266)$ & $70(26.3)$ & $0.714(0.064-8.000)$ & 0.466 \\
\hline \multicolumn{4}{|l|}{ Diabetes } \\
\hline No $(n=544)$ & $132(24.3)$ & 1 & \\
\hline Yes $(n=8)$ & $0(0)$ & - & 0.208 \\
\hline \multicolumn{4}{|l|}{ Respiratory disease } \\
\hline No $(n=535)$ & $126(23.6)$ & 1 & \\
\hline Yes $(n=17)$ & $6(35.3)$ & $1.771(0.642-4.884)$ & 0.257 \\
\hline \multicolumn{4}{|l|}{ Cardiovascular disease } \\
\hline No $(n=548)$ & $130(23.7)$ & 1 & \\
\hline Yes $(n=4)$ & $2(50.0)$ & $3.215(0.448-23.052)$ & 0.243 \\
\hline \multicolumn{4}{|l|}{ Hypertension } \\
\hline No $(n=538)$ & 125 (23.2) & 1 & \\
\hline Yes $(n=14)$ & 7 (50.0) & $3.304(1.137-9.600)$ & 0.049 \\
\hline \multicolumn{4}{|l|}{ Renal disease } \\
\hline No $(n=547)$ & $130(23.8)$ & 1 & \\
\hline Yes $(n=5)$ & $2(40.0)$ & $2.138(0.353-12.937)$ & 0.344 \\
\hline \multicolumn{4}{|l|}{ Liver disease } \\
\hline No $(n=543)$ & 130 (23.9) & 1 & \\
\hline Yes $(n=9)$ & $2(22.0)$ & $0.908(0.186-0.423)$ & 0.999 \\
\hline \multicolumn{4}{|l|}{ Stroke } \\
\hline No $(n=551)$ & $132(24.0)$ & 1 & \\
\hline Yes $(n=1)$ & $0(0)$ & - & 0.999 \\
\hline
\end{tabular}


Tab. 3. Adverse effects and statistical significances according to demographic properties.

\begin{tabular}{|c|c|c|c|}
\hline & $\begin{array}{l}\text { Adverse Effect Present } \\
\text { Prevalence n (\%) }\end{array}$ & OR 95\% CI & $\begin{array}{c}\text { Statistical Significance } \\
\text { P value }\end{array}$ \\
\hline \multicolumn{4}{|l|}{ Age (years) } \\
\hline $20-29(n=95)$ & 34 (35.8) & 1 & \\
\hline $30-39(n=297)$ & $108(36.4)$ & $0.975(0.603-1.579)$ & \\
\hline$\underline{40+\quad(n=59)}$ & $15(25.4)$ & $1.635(0.795-3.361)$ & 0.279 \\
\hline \multicolumn{4}{|l|}{ Sex } \\
\hline Male (n=149) & $38(25.5)$ & 1 & \\
\hline Female(n=302) & $119(39.4)$ & $0.526(0.341-0.813)$ & 0.004 \\
\hline \multicolumn{4}{|l|}{ Diabetes } \\
\hline No $(n=443)$ & 153 (34.5) & 1 & \\
\hline Yes $(n=8)$ & $4(50.0)$ & $0.528(0.130-2.139)$ & 0.458 \\
\hline \multicolumn{4}{|c|}{ Respiratory disease } \\
\hline No $(n=439)$ & $154(35.1)$ & 1 & \\
\hline Yes $(n=12)$ & $3(25.0)$ & $1.621(0.432-6.076)$ & 0.555 \\
\hline \multicolumn{4}{|c|}{ Cardiovascular disease } \\
\hline No $(n=449)$ & $156(34.7)$ & 1 & \\
\hline Yes $(n=2)$ & $1(50.0)$ & $0.532(0.033-8.570)$ & 0.999 \\
\hline \multicolumn{4}{|l|}{ Hypertension } \\
\hline No $(n=443)$ & $155(35.0)$ & 1 & \\
\hline Yes $(n=8)$ & $2(25.0)$ & $1.615(0.322-8.095)$ & 0.719 \\
\hline \multicolumn{4}{|l|}{ Renal disease } \\
\hline No $(n=447)$ & 155 (34.7) & 1 & \\
\hline Yes $(n=4)$ & $2(50.0)$ & $0.531(0.074-3.805)$ & 0.613 \\
\hline \multicolumn{4}{|l|}{ Liver disease } \\
\hline No $(n=443)$ & $153(34.5)$ & 1 & \\
\hline Yes $(n=8)$ & $4(50.0)$ & $0.528(0.130-2.139)$ & 0.458 \\
\hline \multicolumn{4}{|l|}{ Stroke } \\
\hline No $(n=450)$ & 157 (34.9) & 1 & \\
\hline Yes $(n=1)$ & $0(0.0)$ & - & 0.999 \\
\hline
\end{tabular}

\section{Vaccines}

The vaccines used in the campaign were Vaxigrip (Sanofi Pasteur) which included Influenza virus A/New Caledonia/20/99 $\left(\mathrm{H}_{1} \mathrm{~N}_{1}\right)$ like strain IVR-116 15 mcg, Influenza virus A California/7/2004 $\left(\mathrm{H}_{3} \mathrm{~N}_{2}\right.$; NYMC X-157derived from A/New York/55/2004) 15 mcg, and Influenza virus B/Shanghai/361/2002 like strain B/Jiangsu/10/2003 15mcg. The vaccines available at pharmacies were Vaxigrip (Sanofi Pasteur) and Fluarix (GlaxoSmithKline) which included Influenza virus A/New Caledonia/20/99 $\left(\mathrm{H}_{1} \mathrm{~N}_{1}\right) 15$ mcg, Influenza virus A Wisconsin/67/2005 $\left(\mathrm{H}_{3} \mathrm{~N}_{2}\right)$ like strain $15 \mathrm{mcg}$, and Influenza virus B/Malaysia/2506/2004 like strain 15mcg.

\section{Statistical analysis}

Chi-squared test was used to define the significance of the data of health professionals on getting vaccinated for influenza. Univariate logistic regression analysis was used to evaluate the effects of health professionals' properties on the vaccination status. These properties were age, gender, income level, occupation, education level, and presence of chronic diseases. $\mathrm{p}<0.05$ was considered statistically significant.

\section{Results}

\section{Health professionals' characteristics}

Five hundred and fifty-two health professionals were enrolled in the study. Of the health professionals, $67 \%$ (370) were women and $33 \%$ (182) were men. The mean age \pm SD was $33 \pm 5$ (range 23-59) years. Eighty-one percent (492) were married and $11 \%$ (60) were single. Of the primary healthcare professionals $19.6 \%$ (108) were doctors, $15.8 \%$ (87) were nurses, $39.3 \%$ (217) were midwives, $13.4 \%$ (74) were health clerks, $8.5 \%$ (47) were laboratory technicians, $0.9 \%$ (5) were x-ray technicians and $2.5 \%$ (14) were other clerks. There were 342 (62 \%) university graduates, 202 (36 \%) high school graduates, 8 (1.4\%) elementary school graduates. As to the income levels, $0.5 \%$ earned 222 euros or less, $5.8 \%$ earned 223-388 euros, $45.5 \%$ earned 389-833 euros and $48.2 \%$ earned more than 833 euros. Eighty-one percent (450) had no chronic diseases. Respiratory diseases (chronic obstructive pulmonary disease, asthma, emphysema; $n=17$; $3.1 \%$ ), hypertension ( $\mathrm{n}=14 ; 2.5 \%)$, liver disease $(\mathrm{n}=9 ; 1.6 \%)$ diabetes mellitus $(n=8 ; 1.4 \%)$ and hyperthyroidism $(n=7 ; 1.3 \%)$ were the most commonly observed chronic diseases.

\section{Vaccination status}

Overall, 420 (76.1 \%; 95\% confidence interval: CI = 72.379.5) health professionals reported influenza vaccine uptake during the 2006-2007 influenza season. Thirty percent $(n=164)$ reported to have been vaccinated for influenza vaccine in previous seasons. Thirty-seven percent ( $n=207$ ) reported that they would like to get themselves vaccinated for influenza for next season.

In total, 44 (21.6\%) patients were suggested to get their influenza vaccine. Physicians were the ones who most commonly 
suggested vaccination to these patients $(46.2 \%$; $n=25)$. Of the non-vaccinees ( $\mathrm{n}=132 ; 23.9 \%)$, the most commonly cited reason for not getting themselves vaccinated for influenza was that 'the vaccine was not useful' (47.7 \%; $n=63)$. In addition, $29.5 \%(n=39)$ have stated that they were afraid of adverse effects, and 30 (22.7\%) were using other methods for influenza. Of the patients who would like to get themselves vaccinated for influenza for next season $(n=224), 29.0 \%(n=65)$ were suggested to do so by doctors, and $54.9 \%(n=123)$ decided themselves. Two hundred and two (36.6 $\%)$ got vaccinated once during the past five years, 179 (32.4 \%) twice, and 65 (11.8 \%) three times. Their decision for these previous vaccinations was most commonly based on the suggestion of the local health authority ( $\mathrm{n}=206 ; 45.2 \%$ ), own consideration $(n=143 ; 31.4 \%)$, suggestion of doctors ( $n=96 ; 21.1 \%)$.

The vaccines were supplied by the local health authority free of charge ( $n=500 ; 90.5 \%$ ) or obtained from the pharmacy $(n=52$; $9.4 \%$ ). Adverse effects were reported by 157 (28.4\%) health professionals. The adverse effects were reported to include fever $(\mathrm{n}=57 ; 13.5 \%)$, muscle pain $(\mathrm{n}=60 ; 14.2 \%)$, joint pain $(\mathrm{n}=40$; $9.5 \%)$, loss of appetite ( $n=16 ; 3.8 \%)$, headache $(n=41 ; 9.7 \%)$, cough ( $\mathrm{n}=29 ; 6.9 \%)$, malaise $(\mathrm{n}=76 ; 18.0 \%)$, tiredness $(\mathrm{n}=41$; $9.7 \%$ ), stuffiness ( $n=49 ; 11.6 \%)$, sneezing ( $n=54 ; 12.8 \%)$, sore throat ( $\mathrm{n}=33 ; 7.8 \%)$ and others (erythema, edema and abscess at the vaccination site, and lymphadenopathy ( $n=14 ; 3.3 \%)$ (Tab. 1).

Age, gender, marital status, education level, occupation and income level did not have a statistically significant effect on vaccination uptake ( $>>0.05$ ) (Tab. 2). Of the chronic diseases, there was only one statistically significant effect, namely that of having hypertension ( $\mathrm{p}=0.049$ ). Of the ones who had adverse effects, there was no statistically significant relation between adverse effects, age and chronic diseases (Tab. 3). There was only one statistically significant relation, namely that between gender and having adverse effects $(\mathrm{p}=0.004)$. More adverse effects were reported in women than in men.

Univariate logistic regression analysis revealed only the effect of hypertension on vaccination status (odds ratio (OR) at 95\% CI $=3.304$ (1.137-9.600). The possibility of having adverse effects was increased 1.9 times in female health professionals (odds ratio $(\mathrm{OR})$ at $95 \% \mathrm{CI}=0.526(0.341-0.813)$.

\section{Discussion}

This is the fourth study on the attitude and behavior of health professionals. Although the adverse effects of influenza vaccine have been previously defined, this is the first study in literature reporting the adverse effect profile of influenza vaccines for the 2006-2007 season declared by health professionals.

Influenza vaccination has been proven to have clinical and epidemiological benefits. However, its uptake in the general population and among healthcare workers has generally been suboptimal. In the United States, the vaccination rate among healthcare workers was $10 \%$ in 1989, $34 \%$ in 1997, and $40 \%$ in 2003 (9). Despite the fact that the U.S. Advisory Committee on Immunization Practices has recommended influenza immunization among United States healthcare workers to reduce the spread of influenza, the influ- enza immunization coverage among healthcare workers has been less than $50 \%$ (10). The influenza vaccination rate of $76.1 \%$ in our study was reasonably high when compared with the previous studies regarding influenza vaccination in health professionals.

Surveys of healthcare workers have identified various reasons for not getting vaccinated including the concerns about vaccine ineffectiveness and its side effects as well as misconceptions that the vaccine might cause influenza. One study found that the most frequently cited reason for non-acceptance was the fear of side-effects (35\%), avoidance of medications (33\%), reaction to vaccine in the past (24\%), belief that the risk of acquiring influenza was low (18\%), and a dislike for shots (18\%) (11). It was also found that the predictors of acceptance prior the receipt of influenza vaccine were age of at least 50 years, and knowledge that vaccine does not cause influenza (11). Another study found out that advancing age, prior absenteeism, higher socioeconomic status (salary level), and marriage were associated with increased vaccine uptake in various target groups (12). In our study, of the non-vaccinees, the most commonly cited reason for not getting vaccinated for influenza was that 'the vaccine was not useful'. The fear of adverse effects was similar to that in previous studies (29.5 $\%)$. However, age, salary level, and marital status did not have a statistically significant effect on the vaccination status probably due to the presence of campaign.

In a study performed on influenza vaccination among health workers, the subjects said they would be persuaded to take up vaccination in future should there be easier access (36 \%), more information on personal benefits and risks (34\%) as well as more information on effects on staff absence (24\%) (9).

In this study, the threat of a pandemic in the near future, and easy access provided for by the campaign have enhanced the high percentage of vaccination.

Four sudden deaths in men aged between 50 and 75 years with underlying cardiac conditions took place in Israel between 15 and 21 October 2006, while the patients were known to have received influenza vaccine (Vaxigrip) from the same vaccine lot in the days before death. It was very unlikely that there was a causal link between the deaths and the influenza vaccinations (13).

In a study, the reported incidence of side effects from immunization was $13 \%$ while the associated absence from work was low (2\%) (9). Adverse effects reported in our study were relatively higher (28.4\%) but there was no absence from work.

\section{Conclusion}

This study demonstrates that the health professionals in our study group were vaccinated in a reasonably high percentage with influenza vaccine during a campaign. The data of this study suggest that campaigns for vaccinating the health professionals for influenza should be repeated every year in order to achieve high levels of health professional vaccination. The absence of severe or serious adverse effects of the vaccine may be used to encourage both health professionals and patients of primary care. 


\section{4-388}

\section{References}

1. Mandell GL, Bennett JE, Dolin R. Mandell, Douglas, and Bennett's Principles and Practice of Infectious Diseases. New York: Churchill Livingstone, 2000. 1823-1849. In: Treanor JJ. Influenza virus.

2. http://www.cdc.gov/flu/keyfacts.htm 23.09.2004.

3. Vogel GE, Heckler R, Komm Ch, Schottler M, Lange R, Lange W, Wutzler P. Management of influenza in primary care practices. International Congress Series 1263: 499-502, 2000.

4. Wutzler P, Kossow KD, Lode H, Ruf BR, Scholz H, Vogel GE. Antiviral treatment and prophylaxis of influenza in primary care: German recommendations. J Clin Virol 2004; 31 (2): 84-91.

5. Gubareva LV, Matrosovich MN, Brenner MK, Bethell RC, Webster RG. Evidence for zanamivir resistance in an immunocompromised child infected with influenza B virus. J Infect Dis 1998; 178 (5): 1257-1262.

6. Carman WF, Elder AG, Wallace LA et al. Effects of influenza vaccination of health-care workers on mortality of elderly people in long-term care: a randomised controlled trial. Lancet 2000; 355: 93-97.

7. Wong SSY Yuen KY Influenza vaccination: Options and issues Hong Kong Med J 2005; 11: 81-390.
8. Wahid ST, Nag S, Bilous RW, Marshall SM, Robinson AC. Audit of influenza and pneumococcal vaccination uptake in diabetic patients attending secondary care in the Northern Region. Diabet Med 2001; 18: 599-603.

9. Smedley J, Poole J, Waclawski E, Stevens A, Harrison J, Watson J, Hayward A, Coggon D. Influenza immunisation: attitudes and beliefs of UK healthcare workers. Occup Environ Med 2007; 64: 223-227.

10. Salgado CD, Farr BM, Hall KK, Hayden FG. Influenza in the acute hospital setting. Lancet Infect Dis 2002; 2: 145-155.

11. Heimberger T, Chang H, Shaikh M, Crotty L, Morse D, Birkhead G. Knowledge and attitudes of healthcare workers about influenza: why are they not getting vaccinated? Infect Control Hosp Epidemiol 1995; 16: 412-415.

12. Doebbeling B, Edmond M, Davis C, Woodin J, Zeitler R. Influenza vaccination of health care workers: evaluation of factors that are important in acceptance. Preventive Med 1997; 26: 68-77.

13. Surveillance report. Eurosurveillance weekly releases 26 October 2006. 11: 10

Received January 21, 2010. Accepted February 20, 2012. 